\title{
Implementing cognitive behavior therapy for chronic fatigue syndrome in mental health care: a costs and outcomes analysis Korine Scheeres*1, Michel Wensing ${ }^{\dagger 2}$, Gijs Bleijenberg ${ }^{\dagger 1}$ and Johan L Severens ${ }^{\dagger 3,4}$
} \begin{abstract}
Netherlands
Email: Korine Scheeres* - k.scheeres@nkcv.umcn.nl; Michel Wensing - m.wensing@kwazo.umcn.nl; Gijs Bleijenberg - G.Bleijenberg@nkcv.umcn.nl; Johan L Severens - H.Severens@BEOZ.unimaas.nl

* Corresponding author †Equal contributors
\end{abstract}

Address: ${ }^{1}$ Expert Centre Chronic Fatigue, Radboud University Nijmegen Medical Centre (4628), PO Box 9101, 6500 HB, The Netherlands, ${ }^{2}$ Centre for Quality of Care Research, Radboud University Nijmegen Medical Centre, The Netherlands, ${ }^{3}$ Department of Health Organization, Policy and Economics, Maastricht University, The Netherlands and ${ }^{4}$ Department of Clinical Epidemiology and MTA, University Hospital Maastricht, The

Published: 13 August 2008

BMC Health Services Research 2008, 8:175 doi:10.1 186/1472-6963-8-175
Received: 19 September 2007

Accepted: 13 August 2008

This article is available from: http://www.biomedcentral.com//472-6963/8/I75

(c) 2008 Scheeres et al; licensee BioMed Central Ltd.

This is an Open Access article distributed under the terms of the Creative Commons Attribution License (http://creativecommons.org/licenses/by/2.0), which permits unrestricted use, distribution, and reproduction in any medium, provided the original work is properly cited.

\begin{abstract}
Background: This study investigated the costs and outcomes of implementing cognitive behavior therapy (CBT) for chronic fatigue syndrome (CFS) in a mental health center (MHC). CBT is an evidence-based treatment for CFS that was scarcely available until now. To investigate the possibilities for wider implementation, a pilot implementation project was set up.

Method: Costs and effects were evaluated in a non-controlled before- and after study with an eight months time-horizon. Both the costs of performing the treatments and the costs of implementing the treatment program were included in the analysis. The implementation interventions included: informing general practitioners (GPs) and CFS patients, training therapists, and instructing the MHC employees. Given the non-controlled design, cost outcome ratios (CORs) and their acceptability curves were analyzed. Analyses were done from a health care perspective and from a societal perspective. Bootstrap analyses were performed to estimate the uncertainty around the cost and outcome results.
\end{abstract}

Results: 125 CFS patients were included in the study. After treatment $37 \%$ had recovered from CFS and the mean gained QALY was 0.03 . Costs of patients' health care and productivity losses had decreased significantly. From the societal perspective the implementation led to cost savings and to higher health states for patients, indicating dominancy. From the health care perspective the implementation revealed overall costs of $€ 5.320$ per recovered patient, with an acceptability curve showing a $100 \%$ probability for a positive COR at a willingness to pay threshold of $€ 6.500$ per recovered patient.

Conclusion: Implementing CBT for CFS in a MHC appeared to have a favorable cost outcome ratio (COR) from a societal perspective. From a health care perspective the COR depended on how much a recovered CFS patient is being valued. The strength of the evidence was limited by the non-controlled design. The outcomes of this study might facilitate health care providers when confronted with the decision whether or not to adopt CBT for CFS in their institution. 


\section{Background}

Chronic Fatigue Syndrome (CFS) is characterized by persistent or relapsing unexplained fatigue that lasts for at least six months and results in substantial reduction in previous levels of daily functioning [1]. Causes of CFS have not been found and most patients do not recover spontaneously [2]. Based on the CDC-94 criteria, CFS prevalence figures of 112 and 420 per 100.000 were found $[3,4]$.

Cognitive behavior therapy (CBT) has proven to be an effective treatment for CFS $[5,6]$. Since the treatment of CFS with CBT has been available only in a few specialized university medical centers in The Netherlands, just a small minority of CFS patients can benefit from it. Nationwide implementation is needed to realize access to CBT treatment for all CFS patients. However, when decision makers have to judge whether such implementation is worthwhile and should be paid for, they need information about its costs and benefits for individual patients, the healthcare system and society.

The number of cost effectiveness analyses (CEA) of CBT for CFS and chronic fatigue (CF) are few compared to clinical evaluations. One study performed a cost consequence analysis of CBT for CF in general practice compared to regular counseling by a GP. It reported that counselling was a less costly intervention than CBT, and that both interventions led to reductions in fatigue. But no overall costeffectiveness advantage was found for either form of therapy [7]. Another study, concerning a CEA of CBT for CF, [8] found similar cost effectiveness for CBT and graded exercise for CF. It also reported a high probability that these therapies are cost-effective compared to usual care. A third study reported a CEA of CBT for CFS and found, although with some statistical uncertainties, that regarding a time horizon of 14 months, total costs to society were lower for (ex) CFS patients that had followed CBT treatment than for those who had received usual care or guided support groups [9]. Taken together these studies indicate that CBT for CFS or CF might be cost effective for society compared to usual care.

Until now nothing is known about the costs and efficiency of implementing CBT for CFS in a clinical practice setting. It might be possible that the efficiency of CBT for CFS reduces if the implementation costs are high or if the treatment effectiveness reduces. The present study therefore evaluated the broader so-called policy costs and effects of a pilot implementation project in which CBT for CFS was made available in a mental health center (MHC). In a policy study all extra costs of implementing the treatment (like training therapists, informing GPs, organizing and meetings) are being included as fixed costs in the analysis, in addition to the costs and effects of just performing the treatment $[10,11]$.
The MHC of this study was a regional middle-sized institution located in the East of The Netherlands, covering mostly rural and some urbanized areas. It had locations in four separate sub-regions and the CBT for CFS treatment was offered at two of them. This MHC was the main provider of mental health care in this area, offering outpatient and inpatient services for the full range of problems and patients.

\section{Methods \\ Design}

The evaluation was a prospective, non-controlled before and after comparison in a MHC with an observation period of 8 months.

\section{Implementation interventions}

The implementation program contained four major interventions. First, six behavior therapists who were working in the concerning MHC were trained at the Nijmegen Expertcenter for Chronic Fatigue. They were selected on bases of their prior education in CBT and on their willingness and possibility to participate in this implementation project. None of these therapists had previous experience with CFS patients. Their number of years working as a behavioral therapist varied from two to 13 years. Second, because GPs in the region were not familiar with this new treatment setting for CFS, announcements were made in the media and information brochures were distributed to GPs. GPs could also order copies of these brochures for their waiting rooms. Third, informational interventions were performed that were directed at the patient population. These consisted of several media announcements and distribution of patient brochures. Fourth, employees of the mental health care institution were informed and, if applicable, settled into the project.

\section{Patients and treatment procedure}

Patients who attended the treatment were all diagnosed as CFS and referred to the MHC by their GP or a medical specialist. Inclusion criteria were as follows: a GPs diagnosis of CFS (based on the CDC-94 criteria), not enrolled in a new claim for disability-related benefits, and 18 years or older. After the first session the patient had to fill in several fatigue related paper and pencil questionnaires. At 8 months follow up, when treatment was finished, the questionnaire had to be filled in again. Before starting this study it was judged by the Nijmegen Medical Hospital Ethical Commission, who indicated no need for informed consent.

To measure fatigue we used the Checklist Individual Strength (CIS20), which is a self-report measure on a 7point Likert scale for fatigue severity over the last two weeks. The CIS has good reliability (Cronbach's alpha varying from 0,83 to 0,92 ) and discriminative validity [12]. Physical functioning in daily life was measured with the 
'physical functioning' subscale of the SF-36 [13]. This subscale is a validated 10 -item scale with a score varying from 0 (maximum of limitations) to 100 (no limitations). The Euroqol-5d was used to measure QALYs [14].

In some instances this questionnaire results contradicted the diagnosis of CFS. For example, when a psychiatric comorbidity was found that could explain the severe fatigue. In such occasions treatment was not started and the patient was referred to another treatment program in the organization.

The CBT treatment protocol prescribes 16 sessions in a period of 8 months [15]. In this treatment, first the model of psychological and behavioral perpetuating factors of fatigue is explained to the patient. Then the patient formulates his or her goals for therapy. Afterwards the patient starts a structured graded activity program beginning with some daily minutes of walking or bicycling, which is tailored to their base line daily activity level. Subsequently, dysfunctional fatigue related cognitions are being challenged to diminish somatic attributions of fatigue, to improve a sense of control over symptoms and to facilitate behavior change. Finally a plan for work rehabilitation is outlined and worked out. Patients without a paid job focus on rehabilitation in other personal activities. The last session deals with relapse prevention and further improvement of self-control.

\section{Measurement and valuation}

\section{Treatment implementation costs}

Personnel costs, for therapists' trainings, coordinating activities and monthly working group assemblies, were calculated by counting the total amount of hours that concerned people had invested and by multiplying these hours with personnel's gross salary per hour, including $39 \%$ employers' charges. For training and supervision only the hours that were actually attended were calculated, per person. The hours that people had spent on the implementation were counted retrospectively by interviewing concerned people. Traveling costs related to these activities were calculated by summing up the total amount of kilometers by car and counting 0.16 per kilometer. Material costs for informing GPs and patients were determined by summing up al printing, copying and distributing costs of used materials. Accommodation costs were calculated as $10 \%$ of personnel costs [16].

\section{2. $C B T$ integral treatment costs}

For the CBT for CFS treatments integral prices were calculated, implying that all direct (executing) and indirect (overhead) costs of the MHC for offering the treatment were included in the calculation. Total costs of performed treatment sessions were determined by first summing up all therapists, diagnostic assistants and secretaries invested time per treatment. For each patient the total number of attended therapy sessions was registered. Planned sessions that were cancelled less than 24 hours before the session were also calculated. Per session one hour of work was counted for a therapist. Per treated patient 15 minutes secretary work was counted. Per intake and per post treatment session 30 minutes work for a diagnostic assistant was counted. The personnel costs for secretaries and diagnostic assistants were also based on gross salary plus $39 \%$ charges. Then, for overhead costs and building use, 20\% and $10 \%$ respectively of personnel costs were added to the personnel costs [16]. Treatment material costs were too small to count.

\section{Direct medical costs (apart from CBT treatment)}

Volumes of medical consumption were measured with a paper and pencil questionnaire that was filled in by the patient at base line and after treatment. Patients were asked how many visits that they had made in the previous six months to a GP, medical specialist, physiotherapist, psychologist, psychiatrist and alternative medical practitioner. Use of home care support (average hours per week in the last 6 months) hospitalization (number of nights in 6 months) and use of (prescribed and not prescribed) medication were also asked. To value patients' medical consumption, cost prices were used as given in the Dutch cost analyses manual [16] after recalculating them to the 2004 price level (Table 1). Costs of prescribed medication were calculated based on the Dutch indicated market

Table I: Cost-prices used to value the different health care volumes, measured at patient level before and after treatment.

\begin{tabular}{lr}
\hline Health care volume & Cost price \\
\hline General practitioner (per visit) & $€ 20.39$ \\
Medical specialist (per visit) & $€ 63.99$ \\
Physiotherapist (per visit) & $€ 22.96$ \\
Psychologist (per visit) & $€ 125.14$ \\
Psychiatrist (per visit) & $€ 88.81$ \\
Non-physician alternative medicine practitioner (per visit) & $€ 48.87$ \\
Home care (per hour) & $€ 21.90$ \\
Informal home support (per hour) & $€ 8.38$ \\
Hospitalization (per night) & $€ 333.40$
\end{tabular}


prices per month based on 'defined daily doses'. Six percent taxes and 6,51 pharmacy costs per client using medication were added to this market costs. Patients were asked to give a price indication per month of their costs incurred in purchasing over-the-counter medication.

\section{Direct non-medical costs}

For each CFS patient traveling costs for attending the CFS treatment sessions were applied. Distances from patients' homes to the MHC's treatment location were found at http://www.routenet.nl. This distance was multiplied by each patient's total number of attended sessions. Again 0.16 per kilometer was calculated.

\section{Indirect non-medical costs}

Patients' lost productivity costs due to absenteeism from paid work were also measured with the paper and pencil questionnaire. The questionnaire contained questions about work and daily activities, based on the 'Health and Labour Questionnaire' [17]. The number of hours of paid work in the last two weeks was filled in. We valued the days of absenteeism from paid work with Dutch standard productivity costs specified for age, sex and education level [16] and using the human capital method. Transfer payments related to occupational disability insurances were not included since these are neither a gain nor a cost to society [10]. The productivity costs per two weeks were then multiplied by 13 to provide the costs per 6 months.

Informal care measured at baseline and after treatment with a paper and pencil questionnaire about the number of hours per week that patients had received informal care. This was costed at 8.38 per hour [16], the wage rate for a cleaner. Time costs for patients attending the treatment sessions were excluded.

\section{Economic evaluation method Perspective}

Total costs of implementing CBT for CFS were analyzed both from a societal perspective (including also non medical costs such as travelling expenses and productivity costs, regardless of who carried them) and from a health care perspective (indicating that only medical costs were relevant) [10]. For the societal perspective we calculated costs per gained QALY. For the health care perspective instead we calculated costs per recovered patient, being a measure of health rather than a measure of general welfare, which corresponds better to the more limited scope of the health care perspective [18]

\section{Calculation methods}

Total costs were divided into costs for implementing the new treatment (the fixed, so called 'organizing' costs), and costs for facilitating and using the CBT for CFS treatments (the variable, so called 'executing' costs) [19]. Fixed costs were related to assembly- and organizing activities of the working group, informational interventions towards GPs and the public and training and supervising the initial therapists. Variable costs comprised of: 1 . Costs for continuing the treatment facility, comprising of repeatedly providing training and supervision for new therapists (we assumed that because of personnel turnover every two years two new therapist need to be trained and supervised) and continuing PR activities; 2. Costs for clients attending the treatment sessions (e.g. traveling costs); 3 . Costs for organizing and facilitating the treatments (mainly labour costs); 4. Societal costs (including use of healthcare services other than CBT and lost productivity costs due to absenteeism from paid work) and 5. Costs for performing the treatment program (time for therapist performing the treatment sessions, costs for building use, etc).

Because the time period between costs and effects was less then 12 months, we did not apply the principle of discounting. All costs were recalculated to 2004 by using the 2004 'derivative cost-of-living index figures' [20]. All cost prices included in the analyses were valued in terms of integral cost prices [16].

\section{Data analysis \\ Missing data}

in the original database an average of 0.5 cases per item were randomly missing because some patients had failed to answer all questions of a particular questionnaire. These missing data were filled in with the median value for the particular item. In the cases of missing data due to loss of follow up the method of last observation carried forward was used [21], indicating that intake measurements were used as post treatment. Analyses were performed on basis of intention to treat; patients who attended an intake but did not start treatment and patients who dropped out of treatment were all included in the cost analyses.

\section{Cost and outcome calculations}

Given the non-controlled design of the present study, it did not fulfil the criteria of a 'full economic evaluation' $[10]$, and hence the usually calculated incremental costs effectiveness ratios (ICER) could not be analysed. In stead we calculated cost outcome ratios (CORs). Cost outcome ratios (COR) are concerned with the joint difference in costs and outcomes before and after (implementing and) performing a certain treatment [10]. This ratio thus indicates the financial investment that is needed to gain a certain treatment effect, based on the assumption that autonomous change regarding the patients is negligible.

The COR was calculated in two ways. First by defining treatment effect as 'percentage of recovered patients' 
(health care perspective), and second by using quality adjusted life-years (QALYs) as a measure for treatment effect (societal perspective). The recovery rate was analysed by calculating the percentage of patients experiencing significant clinical improvement (CSI). Patients were defined as being CSI at post treatment if they had a reliable change index $>1.96$ on the CIS fatigue severity subscale [22], a fatigue severity score $<=35$ and a Rand-36 physical functioning score $>=65$ [12]. Quality of life was measured using utility scores of the Euroqol [14]. This utility score, lying between 0 (health state equal to death) and 1 (perfect health state), represents the QALY due to some intervention.

Since the health care costs were measured over a period of 6 months, while the individual durations of treatment differed between 2.2 and 16.2 months, all medical and nonmedical costs at follow up were extrapolated to the individually defined treatment period, before including them in the cost outcome analyses.

Utility scores were measured two times, at intake and at follow up. Since the difference in utility scores between the two measurements was presumably reached gradually instead of at once, and because the duration of treatment differed per patient, the gained QALYs at post treatment were calculated as: $0.5^{*}$ (utility score post treatment utility score intake) $/ 12 *$ individual number of months of treatment [10].

\section{Analysis of uncertainty}

Because it was presumed that, as usually, the measured medical costs would follow a skewed distribution, a normality assumption would be problematic when estimating confidence intervals. Therefore the non-parametric bootstrap method [23] was used to quantify the uncertainty of the calculated COR. In the bootstrap method this uncertainty is quantified by plotting cost-effectiveness acceptability (CEA) curves by means of repeated re-sampling of the costs and outcome data (the bootstrapping), which generates a distribution of mean costs and outcomes of two situations [24]. These distributions are then used to calculate the probability that one of the situations is the optimal choice, given a range of possible maximum values (ceiling ratio) that a decision maker might be willing to pay for a unit of improvement in outcome. Because the present study did not calculate cost effectiveness, we used the term 'COR acceptability curve' instead of 'ICER acceptability curve'.

\section{Scenario calculation}

For both the societal and the healthcare perspective, the COR of implementing CBT for CFS in a MHC was also calculated for a period of 5 years.

\section{Results \\ Descriptives}

Figure 1 presents the patient flow. From the 143 patients that entered the MHC during the observation period, 18 'no show' patients never showed up at the intake session. Since they only caused negligible costs they were excluded from this study. The remaining 125 patients were included. At intake 13 patients appeared not to fulfil the diagnostic criteria for CFS, these patients did not start treatment. Of the 112 patients that started treatment, 28 dropped out of treatment quickly after the intake session. Of the 84 patients that followed treatment 12 dropped out half way or later and 72 finished treatment.

\section{Missing data}

At 8 months follow up 74 of the 84 treated patients filled in the questionnaire and 10 patients failed to do this (7 drop out patients and 3 treatment completers). Of the 13 'non CFS' and the 28 'non starting' patients their intake measurements were used as post treatment, since no treatment effect was to be expected within less than 2 sessions.

\section{Sample characteristics}

Patients' characteristics are shown in Table 2. Of the 77 patients $(62 \%)$ that had a paid job (42 fulltime and 35 part time) 54 were actually working and 23 were on sickness benefit.

\section{Treatment characteristics}

The mean duration of the 84 performed treatments was 8.4 months (SD 3.3) and varied from 2.2 to 16.2 months.

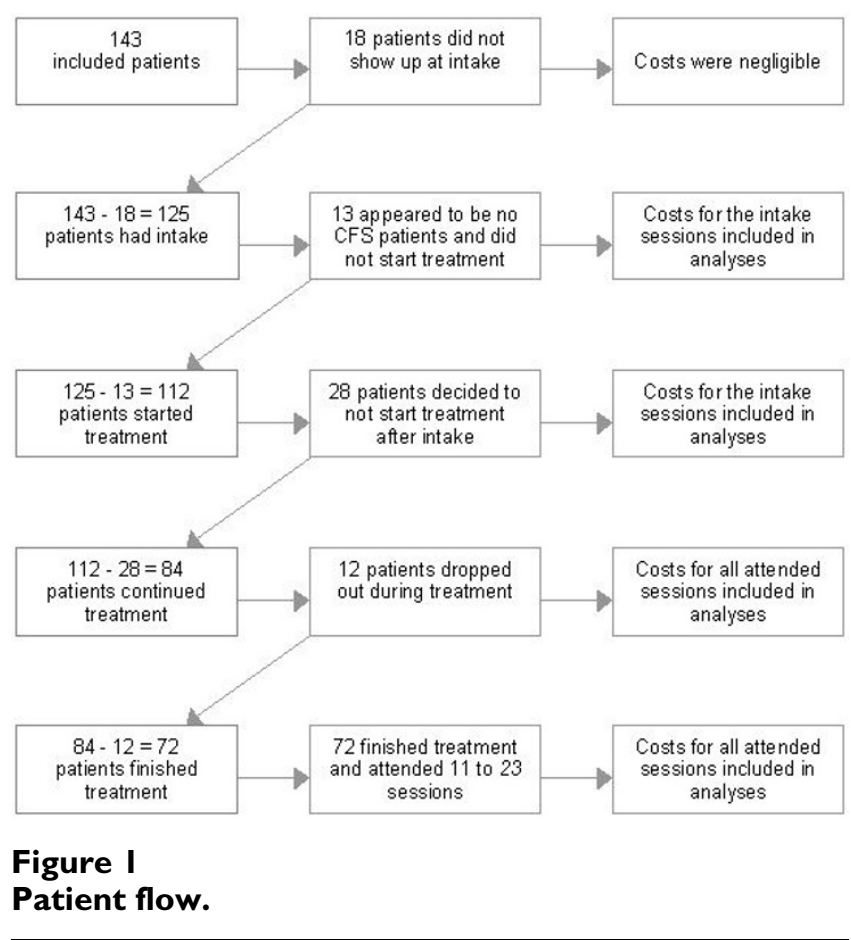


Table 2: Patients' characteristics $(N=$ | 25)

\begin{tabular}{lc}
\hline Categorical variables & $(\mathrm{N} / \%)$ \\
\hline Sex (man/women) & $42(34 \%) / 83(66 \%)$ \\
Higher education & $51(41 \%)$ \\
Having a paid job & $77(62 \%)$ \\
Married/living together/living with parents & $98(78 \%)$ \\
& \\
Continuos variables & $M(\mathrm{SD})$ \\
Age & $38.7(10.2)$ \\
Duration of fatigue (years) & $6.3(7.0)$ \\
Fatigue severity (Cis20) & $48.3(8.0)$ \\
Physical impairment (Rand 36) & $54.0(23.4)$ \\
Social impairment (Rand 36) & $41.5(23.7)$ \\
Psychosocial well-being (SCL-90) & $165.1(42.1)$
\end{tabular}

No relations were found between duration of treatment and several other variables, like treatment effect, decrease in medical consumption or lost productivity costs after treatment. The mean number of treatment sessions was 14.5 (SD 5.6) and varied from 6 to 23 sessions.

\section{Treatment effects}

Effect based on fatigue severity: after treatment 46 of 125 patients (37\%) were recovered. Effect based on Euroqol: the mean utility score at intake was 0.57 (SD 0.27) and post treatment 0.65 (SD 0.30) (table 3).

\section{Costs results}

Table 4 shows the total fixed and variable costs of preparing and introducing the implementation of CBT for CFS, with a total of 90.765 and 59.300 respectively. The costs results of performing and using CBT (table 5) reveal that per patient a mean of 597 were spent per CBT treatment.

Table 6 gives the amounts of medical care other than CBT treatment. These results were used for calculating all (non) medical costs (table 7). As can be seen, total medical costs decreased from 1.112 per six months before treatment to 810 after treatment (95\% CI - 784 to 26). Total non-medical costs also decreased, from 1.249 per six months before treatment to 1.012 after treatment (95\% CI - 813 to 271$)$.

In table 8 the figures on work and absenteeism are given, showing that the mean number of working hours according to contract had fallen from 16.4 per week before treatment to 14.9 after treatment (95\% CI -5.4 to 3.2). The number of real worked hours however had risen from 9.3 before treatment to 11.4 hours per week after treatment ( $95 \%$ CI -2.6 to 5.5), implying that the number of lost productivity hours and its costs decreased, from 218 per patient per week before treatment tot 122 after treatment (95\% CI - 173 to - 6).

\section{Cost outcome ratios}

From the societal perspective the mean societal costs per patient per six months were 8.030 before implementing CBT for CFS and 6.869 after it (95\% CI - 3.489 to $1.083)$. The mean gained QALY per patient was 0,03 . Given the lower cost level and a higher health state of patients, the COR-estimate indicates dominancy. The five years scenario calculation analysis, in which the total amount of treated patients was up-scaled to 3.33 times the amount of patients that were treated in the implementation period of 1,5 years (also figure 2), revealed a greater than $90 \%$ probability for a favorable COR for all acceptability thresholds.

From the health care perspective it was found that mean costs per patient per six months were 1.117 before implementation and treatment and 2.586 after it $(95 \%$ CI 958 to 1.876). Given the recovery rate of $37 \%$ the COR of implementing CBT for CFS was 5.320 per recovered CFS patient. The COR acceptability curve (figure 3 ) shows that the probability that implementing CBT for CFS has a favorable COR is $100 \%$ when the decision maker values a recovered CFS patient at least 6.500 .

The 5 years scenario calculation (also figure 3 ) showed that the $100 \%$ guarantee for an acceptable COR was reached at the willingness to pay threshold of 4.500 .

\section{Sensitivity analysis}

In sensitivity analysis applied for the societal perspective, the costs for (informal) home care and productivity costs were varied. As also has been found in other studies $[7,8]$ (informal) home care appeared to cause major costs. Besides that questions may be raised about the accuracy of the measured amounts of home care. It is a difficult aspect to measure, for example the distinction between informal care and normal household activities is not clearly defined, both for researchers and for patients, especially if the informal caregiver shares a household with the patient [25]. Since patients have a tendency to overestimate their hours of informal care, we performed a calculation reducing informal home care to $50 \%$ and leaving it out at all. In

Table 3: Mean utility scores at intake and 8 months follow up $(N=125)$

\begin{tabular}{lcccc}
\hline & Intake & Follow up & $\Delta$ follow up - intake & $95 \%$ Cl \\
\hline Mean (SD) & $0.57(0.27)$ & $0.65(0.30)$ & $0.078(0.028)$ & 0.03 to 0.09 \\
\hline
\end{tabular}


Table 4: Costs of developing and introducing the implementation of CBT for CFS divided in fixed and variable costs.

\begin{tabular}{|c|c|c|c|}
\hline & Volume & Calculated costs value per volume & Costs \\
\hline \multicolumn{4}{|l|}{ Personnel costs } \\
\hline \multicolumn{4}{|l|}{ Fixed } \\
\hline Therapists & 647 hours & $€ 55.50 /$ hour & $€ 35.909$ \\
\hline Management & 312 hours & $€ 73.17 /$ hour & $€ 22.829$ \\
\hline Others & 793 hours & $€ 35.87 /$ hour & $€ 28.444$ \\
\hline Total fixed & & & $€ 87.182$ \\
\hline \multicolumn{4}{|l|}{ Variable } \\
\hline Therapists & 460 hours & $€ 55.50 /$ hour & $€ 25.530$ \\
\hline Management & 20 hours & $€ 73.17 /$ hour & $€ \mathrm{I} .463$ \\
\hline Supervisor & 266 hours & $€ 62.52 /$ hour & $€ 16.625$ \\
\hline Others & 6 hours & $€ 35.87 /$ hour & $€ 215$ \\
\hline Total variable & & & $€ 43.833$ \\
\hline TOTAL personnel costs & & & $€ 131.015$ \\
\hline \multicolumn{4}{|l|}{ Material costs } \\
\hline \multicolumn{4}{|l|}{ Fixed } \\
\hline Building use & \multicolumn{2}{|c|}{$10 \%$ of personal costs } & $€ 8.718$ \\
\hline PR activities & \multicolumn{2}{|c|}{2000 information letters and brochures } & $€ 1.705$ \\
\hline Total fixed & & & $€ 10.423$ \\
\hline \multicolumn{4}{|l|}{ Variable } \\
\hline Building use & & rsonal costs & $€ 4383$ \\
\hline PR activities & 2500 & etters and brochures & $€ 1.983$ \\
\hline Total variable & & & $€ 6.366$ \\
\hline TOTAL material costs & & & $€ 16.789$ \\
\hline \multicolumn{4}{|l|}{ Traveling costs } \\
\hline \multicolumn{4}{|l|}{ Fixed } \\
\hline Therapists & $3605 \mathrm{~km}$ & $€ 0.18 / \mathrm{km}$ & $€ 649$ \\
\hline Management & $3328 \mathrm{~km}$ & $€ 0.18 / \mathrm{km}$ & $€ 599$ \\
\hline Others & $1411 \mathrm{~km}$ & $€ 0.18 / \mathrm{km}$ & $€ 254$ \\
\hline Total fixed & & & $€ 1.502$ \\
\hline \multicolumn{4}{|l|}{ Variable } \\
\hline Supervisor & $5300 \mathrm{~km}$ & $€ 0.18 / \mathrm{km}$ & $€ 954$ \\
\hline Therapists & 1275 km & $€ 0.18 / \mathrm{km}$ & $€ 230$ \\
\hline Management & $40 \mathrm{~km}$ & $€ 0.18 / \mathrm{km}$ & $€ 7$ \\
\hline Total variable & & & $€ 1.191$ \\
\hline TOTAL traveling costs & & & $€ 2.693$ \\
\hline TOTAL fixed costs & & & $€ 90.675$ \\
\hline TOTAL variable costs & & & $€ 59.300$ \\
\hline TOTAL 'developing and introducing' costs & & & $€ 149.975$ \\
\hline
\end{tabular}

All volumes were valued in terms of Dutch integral cost prices at the price level of 2004 (Oostenbrink et al., 2004).

Table 5: Mean costs per patient (in $€$ ) of using and performing CBT for CFS in mental health care $(\mathbf{N}=$ I25)

\begin{tabular}{|c|c|c|c|c|}
\hline & Mean & $S D$ & Median & Max \\
\hline Personal costs of CBT treatment (only therapist costs) & $€ 417$ & $€ 314$ & $€ 435$ & $€ 1349$ \\
\hline Personal costs of CBT treatment (secretary and test assistants costs) & $€ 28$ & $€ 7$ & $€ 34$ & $€ 34$ \\
\hline Overhead costs and costs for building facilities & $€ 143$ & $€|0|$ & $€ 146$ & $€ 442$ \\
\hline Patients travelling costs (return price) & $€ 9$ & $€ 6$ & $€ 7$ & $€ 43$ \\
\hline TOTAL mean costs per patient of using and performing CBT for CFS & $€ 597$ & $€ 424$ & $€ 628$ & $€ 17892$ \\
\hline
\end{tabular}


Table 6: Volumes of medical consumption (except CGT for CFS treatment) over a period of 6 months measured at patients level at intake and follow up $(\mathrm{N}=125)$.

\begin{tabular}{|c|c|c|c|c|c|c|}
\hline & \multicolumn{3}{|c|}{ Intake } & \multicolumn{3}{|c|}{ Follow up } \\
\hline & $\mathrm{N}$ & Mean (SD) & Median & $\mathrm{N}$ & Mean (SD) & Median \\
\hline \multicolumn{7}{|l|}{ Medical care } \\
\hline GP (number of visits) & 111 & $3.1(3.7)$ & 2 & 93 & $2.0(1.9)$ & 2 \\
\hline Medical specialist (n.o. visits) & 55 & $1.2(1.8)$ & 0 & 38 & $0.9(1.5)$ & 0 \\
\hline Physiotherapist (n.o. visits) & 29 & $3.8(9.0)$ & 0 & 23 & $2.7(7.4)$ & 0 \\
\hline Psychologist, other than CBT for CFS & 22 & $1.0(3.1)$ & 0 & 13 & $0.4(1.4)$ & 0 \\
\hline Psychiatrist (number of visits) & 9 & $0.2(1.2)$ & 0 & 7 & $0.2(1.2)$ & 0 \\
\hline Home care (hours per 6 months) & 21 & $26.9(104.3)$ & 0 & 23 & $22.7(88.4)$ & 0 \\
\hline Hospitalisation (nights) & 13 & $0.4(2.0)$ & 0 & 9 & $0.2(1.5)$ & 0 \\
\hline Prescribed medication (yes/no) & 92 & $77 \%$ & & 87 & $72 \%$ & \\
\hline \multicolumn{7}{|l|}{ Non-medical care } \\
\hline Informal home care (hrs per 6 months) & 37 & I $32.3(268.3)$ & 0 & 33 & $110.6(182.8)$ & 0 \\
\hline Altern. med. practitioner (n.o. visits) & 30 & $1.0(2.3)$ & 0 & 21 & $0.8(2.0)$ & 0 \\
\hline Non prescribed medication (yes/no) & 56 & $53 \%$ & & 27 & $35 \%$ & \\
\hline
\end{tabular}

$\mathrm{N}=$ the number of patients that had been using this form of healthcare

a third calculation both informal and formal home care were omitted from the analyses. These calculations showed that if informal home care was omitted from the analysis, and when both informal and formal homecare were omitted, the probability that implementing CBT for CFS has an acceptable COR remained above $80 \%$ for all acceptability thresholds.

In addition, two extra analyses were done, in which productivity costs were set to $70 \%$ and to $30 \%$ of the original base case level. This revealed a drop in cost savings of CBT to - 16.800 and - 18.730 respectively. It appeared that implementing CBT for CFS remained dominant at both the $70 \%$ and the $30 \%$ level.

Finally, to get an impression of this study's results when compensating for spontaneous recovery, an additional analysis was performed. This was done from the health care perspective, presuming a spontaneous recovering rate of $5 \%$ [2], implying a recovery rate due to treatment of $32 \%$. It revealed that the COR would rise from 5.320 to about 5.969 per recovered patient.

Table 7: Mean medical and non-medical costs per 6 months measured at patient level at intake and follow up $(N=125)$.

\begin{tabular}{|c|c|c|c|c|c|c|}
\hline & \multicolumn{3}{|c|}{ Intake } & \multicolumn{3}{|c|}{ Follow up } \\
\hline & Mean & $S D$ & Median & Mean & $S D$ & Median \\
\hline \multicolumn{7}{|l|}{ Medical costs } \\
\hline GP & $€ 63$ & $€ 67$ & $€ 4 I$ & $€ 41$ & $€ 40$ & $€ 4 I$ \\
\hline Medical specialist & $€ 77$ & $€ 103$ & $€ 0$ & $€ 58$ & $€ 95$ & $€ 0$ \\
\hline Physiotherapist & $€ 87$ & $€ 202$ & $€ 0$ & $€ 62$ & $€|8|$ & $€ 0$ \\
\hline Psychologist & $€ 125$ & $€ 377$ & $€ 0$ & $€ 50$ & $€ 172$ & $€ 0$ \\
\hline Psychiatrist & $€ 18$ & $€ 107$ & $€ 0$ & $€ 18$ & $€ 95$ & $€ 0$ \\
\hline Home care & $€ 589$ & $€ 1629$ & $€ 0$ & $€ 498$ & $€ 1235$ & $€ 0$ \\
\hline Hospitalisation & $€ 134$ & $€ 720$ & $€ 0$ & $€ 67$ & $€ 509$ & $€ 0$ \\
\hline Prescribed medicine & $€ 19$ & $€ 50$ & $€ 3$ & $€ 16$ & $€ 52$ & $€ 3$ \\
\hline \multicolumn{7}{|l|}{ Non medical costs } \\
\hline Alternative med. pr. & $€ 56$ & $€ 114$ & $€ 0$ & $€ 39$ & $€ 94$ & $€ 0$ \\
\hline Non prescr. medicine & $€ 52$ & $€ 121$ & $€ 0$ & $€ 25$ & $€ 53$ & $€ 0$ \\
\hline Informal homecare & $€ 1109$ & $€ 2322$ & $€ 0$ & $€ 927$ & $€ 1573$ & $€ 0$ \\
\hline Travelling costs & $€ 32$ & $€ 32$ & $€ 23$ & $€ 21$ & $€ 28$ & $€ \mathrm{II}$ \\
\hline Total medical costs & $€ 1112$ & $€ 2258$ & $€ 362$ & $€ 810$ & $€ 1350$ & $€ 24 I$ \\
\hline Total non-medical costs & $€ 1249$ & $€ 2396$ & $€ 112$ & $€ 1012$ & $€ 1822$ & $€ 72$ \\
\hline
\end{tabular}


Table 8: Patient volumes of work and lost productivity costs per week, measured at patient level before and after treatment $(\mathbf{N}=$ 125).

\begin{tabular}{lrrrrrrrr}
\hline & \multicolumn{3}{c}{ Intake } & & \multicolumn{3}{c}{ Follow up } \\
& Mean & SD & Median & Max & Mean & SD & Median & Max \\
\hline Number of contract hours & 16.2 & 16.3 & 10 & 40 & 14.9 & 16.2 & 7 & 40 \\
Number of worked hours & 9.4 & 13.5 & 0 & 45 & 11.4 & 14.7 & 0 & 46 \\
Absenteeism in hours & 7.4 & 12.3 & 0 & 40 & 4.1 & 8.8 & 0 & 40 \\
Lost productivity costs & $€ 218$ & $€ 392$ & $€ 0$ & $€ 1544$ & $€ 122$ & $€ 292$ & $€ 0$ & $€ 1544$ \\
\hline
\end{tabular}

\section{Discussion}

This study has shown that from a societal perspective the cost outcome ratio (COR) after implementing CBT for CFS in a MHC was dominant compared to before. From a healthcare perspective the COR after implementation was more costly but also more effective than before, and the $100 \%$ probability that the COR is acceptable was reached at the willingness to pay threshold of 4.500 is positive. Given that CBT is the only effective treatment for CFS and has been scarcely available until now, this is relevant information in favor of nationwide implementation. Although some studies have already examined the cost effectiveness of behavioral treatments for chronic fatigue (CF) $[7,8]$ and for CFS [9], there has been no research into the cost effectiveness of such a treatment that also took into account the costs of designing the implementation interventions needed for implementing the treatment and the costs of actually implementing the treatment in a nonacademic setting. Such a study implies a less homogenous patient population and less control over the content of performed treatment sessions than an academic setting can guarantee.

Concerning age and gender, the patient population was fully representative of the CFS population. Compared to other trials in the area of CFS, the baseline fatigue severity

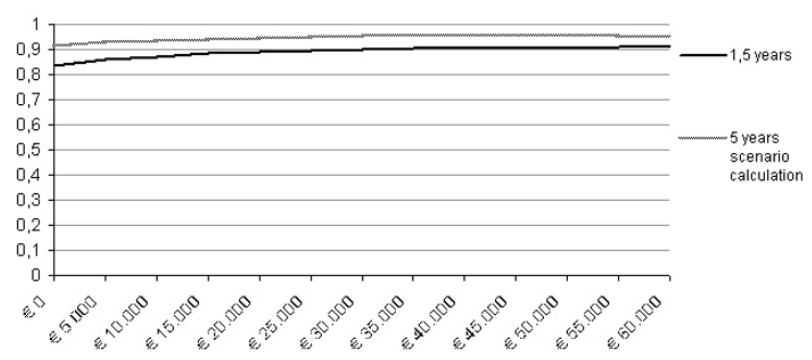

Figure 2

Acceptability curve showing the probability that implementing CBT for CFS has a favorable cost outcome ratio over a range of willingness to pay regarding societal costs per QALY. Societal willingness to pay for a CFS patient's gained QALY. was a little lower and relatively many patients had a paid job $[26,27]$. These differences could be explained by the fact that the treatment facility at the mental health care institution was more easily accessible. Patients may be recognized as CFS by their GP and referred to CBT in an earlier phase than patients referred (mostly by a medical specialist) to a specialized hospital setting.

As was also found in earlier cost effectiveness studies, $[8,9]$ an overall lower use of health care facilities was measured after CBT for CFS than before it. This may be explained by the fact that during treatment with CBT patients are instructed not to use other treatments or medication and by the fact that when starting treatment all patients were diagnosed as CFS. Looking for a diagnosis and a lack of affective treatment are the main reasons for CFS patients' high use of health care facilities [28]. Concerning work productivity, fewer patients had a paid job after treatment than before, but the mean hours of paid work per week had increased after treatment. Given the short time horizon (8 months) the full influence of CBT for CFS on work productivity might be revealed to be larger and the impact on cost-effectiveness more pronounced.

In this study we used a conservative method, last observation carried forward, in cases of missing data. This imputation method might have influenced the results in a conservative, negative direction. However the proportion

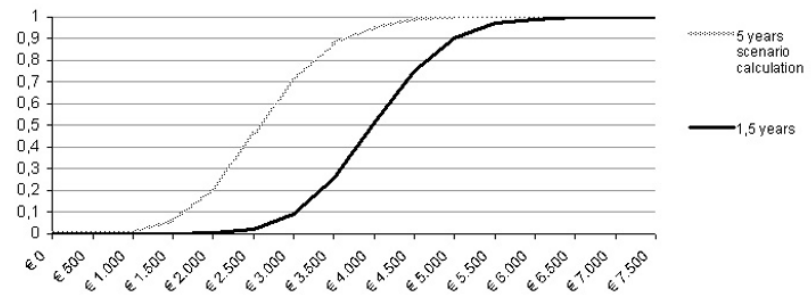

Figure 3

Acceptability curve showing the probability that implementing CBT for CFS has a favorable cost outcome ratio over a range of willingness to pay regarding health care costs per recovered patient.

Willingness to pay for recovering a CFS patient. 
of missing data was in our opinion rather small $(<12 \%)$ thus the chance that significantly different results were obtained is small.

A serious limitation of this study is it's non-controlled before and after design, which implies that incremental cost effectiveness compared to a natural course control group, or compared to a guided support group controlling for any placebo effect, could not be analysed. However, the incremental cost effectiveness ratio (ICER) of CBT for CFS compared to usual care was recently reported by Severens et al. [9]. The focus and contribution of the present study was primarily to investigate costs and consequences of implementing this evidence based treatment in a clinical practice setting. This is a relevant issue in bridging the gap between science and research, since proven (cost) effectiveness under laboratory conditions of RCTs does not guarantee the same in the practice field of health care. Both smaller treatment effects due to the less controlled situation and accompanying costs of including costs for implementing the treatment might change the cost-outcome ratio.

Another weak point in this study is the variable follow up time. Although the mean time period between intake and post treatment was 8.4 months, and analyses were done using this time horizon for all patients, the real time interval varied considerable. The problem hereby is that in fact we do not know what this implies for the results that were found.

A strong point though is the fact that, besides the usual included medical-, productivity-, and patient related costs also protocol driven- and implementation related costs were included [29], giving a more complete and more relevant view on the cost and outcomes of providing nationwide CBT for CFS.

\section{Conclusion}

To conclude, the results of this study suggest that implementing cognitive behavioral therapy for chronic fatigue syndrome in a mental health center is feasible and advisable. This strategy appeared to be dominant (resulting in lower costs and higher health states) compared to the starting situation from a societal perspective. From a health care perspective the implementation also implied better health states, but also higher costs, and the probability of a positive cost outcome ratio depended on how much value is placed on a recovered CFS patient. The outcomes of this study might facilitate the decision for health care providers whether or not to adopt CBT for CFS in their institution.

\section{Competing interests}

The authors declare that they have no competing interests.

\section{Authors' contributions}

KS collected all data, performed the statistical analysis together with JLS and wrote manuscript. JLS contributed to the development of the study design concentrating on the costs aspects, advised about the performance of the statistical analysis, checked the analysis and results and provided the Bootstrap program. MW contributed to the development of the study design concentrating on the implementation outcome aspects and revised the manuscript critically several times. GB delivered the treatment outcome measurement scales, helped with interpreting the results and helped to draft the manuscript. All authors read and approved the final manuscript.

\section{Acknowledgements}

None

\section{References}

I. Fukuda K, Strauss SE, Hickie I, Sharpe MNC, Dobbins JG, Komaroff $A$ : The chronic fatigue syndrome: a comprehensive approach to its definition and study. Annual Internal Medicine 1994, 21:953-959.

2. Cairns R, Hotopf $M$ : A systematic review describing the prognosis of chronic fatigue syndrome. Occup Med 2005, 55:20-31.

3. Bazelmans E, Vercoulen JHMM, Swanink CMA, Fennis JFM, Galama JMD, van Weel C, Meer JWM van der, Bleijenberg G: Chronic fatigue syndrome and primary fybromyalgia syndrome as recognised by GPs. Fam Pract 1999, 16(6):602-604.

4. Reyes M, Nisenbaum R, Hoaglin DC: Prevalence and incidence of chronic fatigue syndrome in Wichita, Kansas. Arch Intern Med 2003, 163:1530-1536.

5. Whiting P, Bagnall A, Sowden AJ, Cornell JEW, Mulrow CD, Ramirez $G$ : Interventions for the treatment and management of chronic fatigue syndrome. JAMA 200I, 286:1360-66.

6. Afari N, Buchwald D: Chronic fatigue syndrome: a review. $A m \mathrm{~J}$ Psychiatry 2003, 160:221-236.

7. Chisholm D, Godfrey E, Ridsdale L, Chalder T, King M, Seed P, Walace P, Wessely S: Chronic fatigue in General Practice: economic evaluation of counseling versus cognitive behavioral therapy. Br J Gen Pract 200I, 5 I (462): I5-8.

8. McCrone P, Ridsdale L, Darbishire L, Seed P: Cost effectiveness of cognitive behavioral therapy, graded exercise and usual care for patients with chronic fatigue in primary care. Psychol Med 2004, 34:99I-999.

9. Severens LJ, Prins JB, Wilt GJ van der, Meer JWM van der, Bleijenberg $\mathrm{G}$ : Cost-effectiveness of cognitive behaviour therapy for patients with chronic fatigue syndrome. Q J Med 2004, 97(3): $|53-16|$.

10. Drummond MF, O'Brien BJ, Stoddart GL, Torrance GW: Methods for economic evaluation of health care programs 2 nd edition. Oxford Medical Publications; 1997.

II. Mason J, Freemantle N, Nazareth I, Eccles M, Haines A, Drummond $M:$ When is it cost-effective to change the behaviour of health professionals? JAMA 200I, 286(23):2988-2992.

12. Vercoulen JHMM, Swanink CMA, Galama JMD, Fennis JFM, Meer JWM van der, Bleijenberg G: Dimensional assessment in chronic fatigue syndrome. J Psychosom Res 1994, 38:383-392.

13. Stewart AL, Hays RD, Ware JE jr: The MOS short form general health survey: reliability and validity in a patient population. Med Care 1988, 26:724-735.

14. Dolan P: Modelling valuations for Euroqol Health states. Med Care 1997, 35: 1095-108. 
15. Bazelmans E, Prins JB, Bleijenberg G: Cognitive behavior therapy for relatively active and for passive CFS patients. Cogn Behav Pract 2006, I3:157-166.

16. Oostenbrink JB, Koopmanschap ME, Rutten FFH: Manual for Cost Analysis, Method and Guidelines Prices for economic Evaluation in Health Care Amstelveen, College voor Zorgverzekeringen (In Dutch); revised version; 2004.

17. van Roijen L, Essink-Bot ML, Koopmanschap MA, Bonsel G, Rutten FF: Labor and health status in economic evaluation of health care. The Health and Labor Questionnaire. Int J Technol Assess Health Care 1996, I 2:405-4I5.

18. Tsuchiya A, Williams A: Welfare economics and economic evaluation. In Economic evaluation in health care: merging theory and practice Edited by: Drummond M, McGuire A. Oxford University Press; $200 \mathrm{I}$.

19. Severens JL: Value for money of changing healthcare services? Economic evaluation of quality improvement. Qual Saf Health Care 2003, I 2:366-37I.

20. The Dutch Bureau of Statistics (Centraal Bureau voor de Statistiek) [http://www.cbs.nl/nl-NL/menu/themas/prijzen/cijfers/ default.htm]

21. Oostenbrink JB, AI MJ: The analysis of incomplete cost data due to drop out. Health Econ 2005, I4(8):763-776.

22. Jacobsen NS, Truax P: Clinical significance: a statistical approach to defining meaningful change in psychotherapy research. J Consult Clin Psychol 199I, 59:12-19.

23. Briggs AH: Pooling cost-effectiveness analysis up by its bootstrap: a non-parametric approach to confidence interval estimation. Health Econ 1997, 6(4):327-340.

24. Briggs $A$ : Handling uncertainty in economic evaluation and presenting the results. In Economic evaluation in health care: merging theory and practice Edited by: Drummond M, McGuire A. Oxford University Press; 200I.

25. Berg B Van der, Brouwer W, van Exel J, Koopmanschap M: Economic evaluation of informal care: the contingent valuation method applied to informal caregiving. Health Econ 2005, I4:169-183.

26. Prins JB, Bleijenberg G, Bazelmans E, Elving L, de Boo T, Severens JL, et al.: Cognitive behaviour therapy for chronic fatigue syndrome: a multicenter randomised controlled trial. The Lancet 200I, 257:84I-847.

27. Stulemeijer M, de Jong LW, Fiselier TJ, Hoogveld SW, Bleijenberg G Cognitive behaviour therapy for adolescents with chronic fatigue syndrome: a randomised controlled trial. $\mathrm{Br} M e d \mathrm{~J}$ 2005, 330:14-18.

28. Bombardier $\mathrm{CH}$, Buchwald DM: Chronic fatigue, chronic fatigue syndrome and fybromyalgia: disability and health care use. Med Care 1996, 34(9):924-930.

29. Hoomans T, Evers SMAA, Ament A, Hubben M, Weijden T Van der, Grimshaw J, Severens JL: Methodological quality of economic evaluations of guideline dissemination and implementation strategies: systematic review of empirical studies. Value Health 2007, I0(4):305-316.

\section{Pre-publication history}

The pre-publication history for this paper can be accessed here:

http://www.biomedcentral.com/1472-6963/8/175/pre pub
Publish with Biomed Central and every scientist can read your work free of charge

"BioMed Central will be the most significant development for disseminating the results of biomedical research in our lifetime. "

Sir Paul Nurse, Cancer Research UK

Your research papers will be:

- available free of charge to the entire biomedical community

- peer reviewed and published immediately upon acceptance

- cited in PubMed and archived on PubMed Central

- yours - you keep the copyright

Submit your manuscript here:

http://www.biomedcentral.com/info/publishing_adv.asp
BiolMedcentral 